\title{
A SIMPLIFIED PROCEDURE FOR DETERMINATION OF CLOFENTEZINE RESIDUES IN FRUITS BY LIQUID CHROMATOGRAPHY WITH UV DETECTION
}

\author{
Sandro Navickiene and Maria Lúcia Ribeiro* \\ Departamento de Química Orgânica, Instituto de Química, Universidade Estadual Paulista, CP 355, 14801-970 Araraquara - SP
}

Recebido em 7/10/03; aceito em 23/1/04; publicado na web em 17/6/04

\begin{abstract}
A rapid and sensitive method is described for the determination of clofentezine residues in apple, papaya, mango and orange. The procedure is based on the extraction of the sample with a hexane:ethyl acetate mixture $(1: 1, \mathrm{v} / \mathrm{v})$ and liquid chromatographic analysis using UV detection. Mean recoveries from 4 replicates of fortified fruit samples ranged from $81 \%$ to $96 \%$, with coefficients of variation from $8.9 \%$ to $12.5 \%$. The detection and quantification limits of the method were of 0.05 and $0.1 \mathrm{mg} \mathrm{kg}^{-1}$, respectively.
\end{abstract}

Keywords: fruits; clofentezine; pesticides.

\section{INTRODUCTION}

Clofentezine, 3,6-bis (2-chlorophenyl)-1,2,4,5-tetrazine, is a specific acaricide with contact action, and long residual activity, Figure 1. It is used for control of eggs and young stages of Panonychus ulmi and Tetranychus spp. on pome fruit, stone fruit, citrus fruit, nuts, vines, hops, strawberries, cucurbits, cotton and ornamentals ${ }^{1,2}$. In Brazil, clofentezine has been released by the legislation for field application on apple, citrus, and cotton ${ }^{3}$.

Few methods for determining clofentezine in fruit (apple, plum, melon and strawberry) have been described in the literature. They include liquid-liquid or supercritical fluid extraction. Gel permeation chromatography has been used as purification technique. Analyses have been carried out by liquid chromatography with UV diodearray and/or mass selective detection or gas chromatography with electron-capture detection ${ }^{4-8}$.

To date no research has been reported about the determination of clofentezine using $\mathrm{NH}_{2}$ analytical column. Besides, Brazil plays an important role in the worldwide fresh fruit production, which is seriously affected by the occurrence of pests and diseases. Tropical fruits as mango and papaya are important international trade itens, so it is necessary to evaluate the fruit contamination by pesticides to avoid export problems. Therefore, the main objective of this work was to investigate the performance of a method for the determination of clofentezine residues in apple, mango, orange and papaya samples. This method involves a small-scale extraction and quantification by means of liquid chromatography using ultraviolet detection.

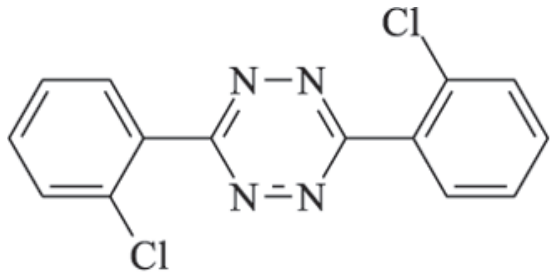

Figure 1. Molecular structure of clofentezine

\section{EXPERIMENTAL PART}

\section{Chemicals}

Ethyl acetate, dichloromethane, methanol and hexane were nanograde (Mallinckrodt Baker Inc., Paris, Kentucky, USA). Anhydrous sodium sulfate was analytical grade (Mallinckrodt Baker Inc., Paris, Kentucky, USA). Purified water- LC-grade water was obtained by filtering deionized water through a $0.45 \mu \mathrm{m}$ filter with a Waters Millipore (Milford, MA, USA) system. Methanol and water were degassed using a Branson 5200 (Branson Ultrasonic Corporation, Danbury, CT, USA) ultrasonic bath.

Reference standard of clofentezine was purchased from Dr. Ehrenstorfer (Augsburg, Germany). The standard was $99.4 \%$ pure. The stock solution of the analyte was prepared by diluting $1.0 \mathrm{mg}$ of the standard in $10.0 \mathrm{~mL}$ of dichloromethane to obtain a concentration of $100 \mu \mathrm{g} \mathrm{mL}^{-1}$. The working solutions were prepared by appropriate dilution of stock solution in ethyl acetate:hexane $(1: 1, \mathrm{v} / \mathrm{v})$.

\section{Apparatus}

Waters liquid chromatograph (Waters Assoc., Milford, MA, USA) equipped with two solvent delivery pumps (Model 501), injector (Model U6K), UV-Vis absorbance detector (Model 486) and a reporting integrator (Model 746) was used for the determination of clofentezine. A stainless steel analytical column Nucleosil $\mathrm{NH}_{2}(250$ x $4.6 \mathrm{~mm}$ i.d., $5 \mu \mathrm{m}$; Phenomenex, Torrance, CA, USA) connected to a Nucleosil $\mathrm{NH}_{2}$ guard column $(20$ x $4.6 \mathrm{~mm}$ i.d., $5 \mu \mathrm{m}$; Phenomenex, Torrance, CA, USA) was used. The compound was analysed by an isocratic mode consisted of methanol-water (70:30, $\mathrm{v} / \mathrm{v}$ ) at flow rate of $0.8 \mathrm{~mL} \mathrm{~min}^{-1}$ using UV absorption at $254 \mathrm{~nm}$.

\section{Sample preparation and fortification}

Apple, papaya, mango and orange samples were bought from local markets. The fruits were triturated separately using a household blender, and stored in closed glass flasks at $-18^{\circ} \mathrm{C}$. Fortified samples were prepared by adding $1.0 \mathrm{~mL}$ of standard solution to $20 \mathrm{~g}$ of sample.

\section{Method}

A $5 \mathrm{~g}$ portion fruit sample was weighed into a glass-stoppered 
flask. A $10.0 \mathrm{~mL}$ of hexane:ethyl acetate mixture (1:1, v/v) were added and the flask was shaken for $20 \mathrm{~min}$ on mechanical shaker (Thermolyne, Dubuque, Iowa, USA). The organic layer was poured to another flask containing anhydrous sodium sulfate. An aliquot of $20 \mu \mathrm{L}$ was injected into the LC-UV system.

\section{RESULTS AND DISCUSSION}

The separation of the clofentezine was conducted on a Nucleosil $\mathrm{NH}_{2}$ column with an isocratic method. The mixture methanol/water was used as mobile phase. To evaluate the mobile phase, different ratios of methanol-water were tested with respect to optimal peak sharpness, separation efficiency and short elution time. The methanolwater isocratic elution (70:30) at $254 \mathrm{~nm}$ shows the best conditions with respect to the analysis of the pesticide investigated. The chromatograms of the fruit extracts were satisfactory, without any interference in the time area of the acaricide. Figure 2 shows the chromatograms of control and fortified apple samples and standard solution of clofentezine. The total running time of LC-UV analysis was $15 \mathrm{~min}$.

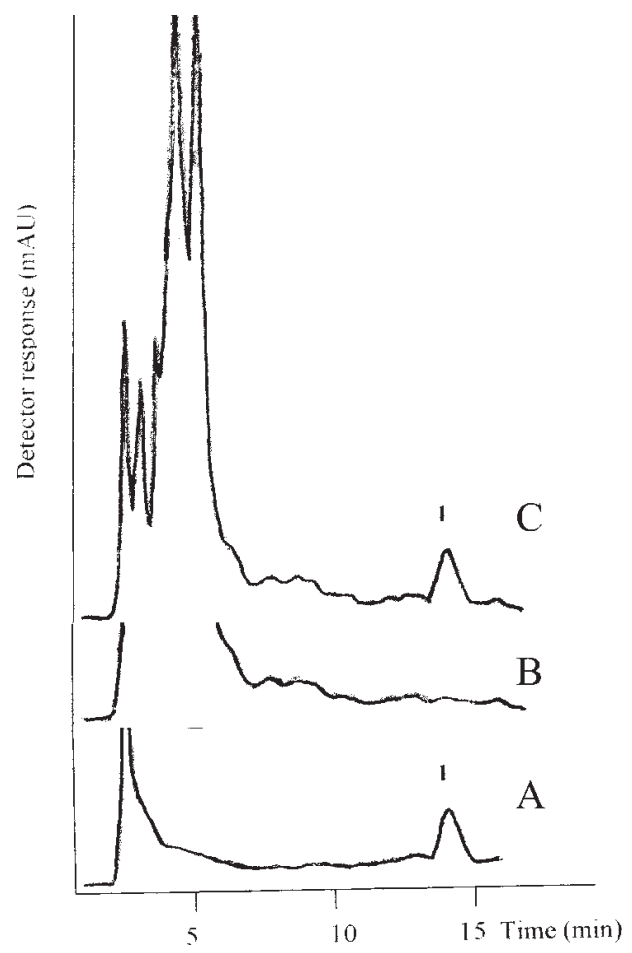

Figure 2. LC-UV chromatograms of: (A) standard solution of (1) clofentezine $\left(0.1 \mathrm{mg} \mathrm{kg}^{-1}\right),(B)$ untreated apple sample and $(C)$ apple sample fortified with clofentezine $\left(0.1 \mathrm{mg} \mathrm{kg}^{-1}\right)$. Conditions: analytical column Nucleosil $\mathrm{NH}_{2}(250 \times 4.6 \mathrm{~mm}$ i.d., $5 \mu \mathrm{m})$ connected to a Nucleosil $\mathrm{NH}_{2}$ guard column (20 $x 4.6 \mathrm{~mm}$ i.d., $5 \mu \mathrm{m})$. Mobile phase (isocratic mode): methanol:water (70:30), flow rate: $0.8 \mathrm{~mL} \mathrm{~min} \mathrm{~m}^{-1} ; \lambda=254 \mathrm{~nm}$; injection volume: $20 \mu \mathrm{L}$

In preliminary investigations performed for choosing the extraction solvent, the mixture ethyl acetate:n-hexane $(1: 1, \mathrm{v} / \mathrm{v})$ was selected, once it presented the highest recoveries (80-90\%) for the compound extraction from apple, mango, orange and papaya. The recovery tests using ethyl acetate were in the range of $90-110 \%$. Also, a higher background and more interfering peaks in the chromatograms were observed using ethyl acetate as extraction solvent. For the recovery experiments were used blank fruit samples previously determined not to contain pesticide of interest. Recoveries were calculated by comparison with the appropriate working standard solutions. A $20 \mathrm{~g}$ portion of untreated fruit was fortified at different concentrations $\left(0.1,0.2,1.0\right.$ and $\left.2.0 \mathrm{mg} \mathrm{kg}^{-1}\right)$ and quantified by using the external standard method. Standard solutions were injected after every ten samples to monitor changes in chromatographic conditions. The Brazilian legislation establishes maximum residue limits (MRLs) for clofentezine for citrus and apple matrices. The MRL values are 0.2 and $0.1 \mathrm{mg} \mathrm{kg}^{-1}$, respectively. The fortification levels used for mango and papaya were chosen once these levels are found within the values of international maximum residue levels for clofentezine in these fruit matrices, 2.0 and $1.0 \mathrm{mg} \mathrm{kg}^{-1}$, respectively ${ }^{9,10}$. The results of the average recoveries ranged from 81 to $96 \%$, with relative standard deviation (RSD) values of 8.9 to $12.5 \%$, as can be seen in Table 1 . Each recovery analysis was repeated 4 times. The precision and accuracy were considered adequate for the validation of the method according to the validation criteria ${ }^{11}$.

Table 1. Recoveries of clofentezine from fortified fruit samples employing LC-UV $(* n=4$ replicates)

\begin{tabular}{|c|c|c|c|}
\hline Acaricide & Matrix & $\begin{array}{l}\text { Spiked level } \\
\left(\mathrm{mg} \mathrm{kg}^{-1}\right)\end{array}$ & $\begin{array}{c}\% \text { Range of recovery* } \\
(\% \text { mean; \%RSD) }\end{array}$ \\
\hline \multirow[t]{12}{*}{ clofentezine } & apple & 0.1 & $\begin{array}{c}85-97 \\
(88 ; 9.8)\end{array}$ \\
\hline & & 1.0 & $\begin{array}{c}76-89 \\
(83 ; 8.9)\end{array}$ \\
\hline & & 2.0 & $\begin{array}{c}85-101 \\
(91 ; 11.5)\end{array}$ \\
\hline & papaya & 0.1 & $\begin{array}{c}79-108 \\
(91 ; 10.9)\end{array}$ \\
\hline & & 1.0 & $\begin{array}{c}75-92 \\
(85 ; 10.5)\end{array}$ \\
\hline & & 2.0 & $\begin{array}{c}79-88 \\
(84 ; 9.8)\end{array}$ \\
\hline & orange & 0.1 & $\begin{array}{c}82-109 \\
(94 ; 10.4)\end{array}$ \\
\hline & & 1.0 & $\begin{array}{c}70-98 \\
(81 ; 11.8)\end{array}$ \\
\hline & & 2.0 & $\begin{array}{c}81-108 \\
(96 ; 12.5)\end{array}$ \\
\hline & mango & 0.1 & $\begin{array}{c}87-96 \\
(93 ; 11.1)\end{array}$ \\
\hline & & 1.0 & $\begin{array}{c}72-94 \\
(81 ; 11.2)\end{array}$ \\
\hline & & 2.0 & $\begin{array}{c}80-94 \\
(86 ; 10.1)\end{array}$ \\
\hline
\end{tabular}

$\mathrm{RSD}=$ relative standard deviation

Under the chromatographic conditions described, good linearity and correlation coefficient were achieved for the clofentezine. Replicates $(n=3)$ of the standard pesticide solutions of different concentrations were analysed and the detector response (peak area) was plotted against concentrations. The correlations were found to be linear in the range from 0.05 to $4.0 \mu \mathrm{g} \mathrm{mL}^{-1}$. The correlation coefficient obtained for the pesticides was 0.9998 .

Repeatability of the retention time and peak areas were examined by using a $0.5 \mathrm{ng} \mu \mathrm{L}^{-1}$ standard solution of the acaricide. Three replicate injections were carried out within a day. The results obtained showed that the pesticide peak area variabilities for standard solution were within 3.6\% RSD. Retention times showed the maximum RSD values of $1.2 \%$.

The criteria established by Thier and Zeumer to find limit of detection (LOD) and quantification (LOQ) were used in this study. 
The LOD for clofentezine was $0.05 \mathrm{mg} \mathrm{kg}^{-1}$. The LOQ were determined as the lowest concentration of the clofentezine that gives a response that could be quantified with a RSD of less than $20 \%$ and a recovery at least $70 \%$. So, the LOQ value for this compound was $0.1 \mathrm{mg} \mathrm{kg}^{-112}$.

Table 2 shows some differences between the method studied and the Balinova ${ }^{4}$ and Gelsomino ${ }^{6}$ methods. The comparison emphasizes the recovery values, coefficients of variation, extraction and cleanup procedures. Also these methods require a large volume of solvent and large amount of sample. The present method has comparable results at the same level of concentration $\left(\right.$ Balinova $\left.^{4}\right)$ and emphasizes the reduced number of steps involved in the analytical procedure.

The method was applied to the analysis of 126 real fruit samples (apple, mango, orange and papaya) obtained from commercial markets located in Araraquara, São Carlos, Jaboticabal and Ribeirão Preto cities, São Paulo State, Brazil. Clofentezine residues were not detected in these samples under the experimental conditions described.

Table 2. Comparison of the literature methods and the present method for the determination of clofentezine residues in fruit

\begin{tabular}{|c|c|c|c|c|}
\hline \multirow{3}{*}{$\begin{array}{c}\text { Clofentezine } \\
\text { Matrix } \\
{[\mathrm{g}]}\end{array}$} & \multirow{3}{*}{$\begin{array}{l}\text { Spiked Level } \\
\quad\left(\mathrm{mg} \mathrm{kg}^{-1}\right) \\
\text { [solvent, } \mathrm{mL}]\end{array}$} & \multicolumn{2}{|c|}{ Analytical procedure } & \multirow[t]{3}{*}{ Average (\%RSD) } \\
\hline & & Extraction & Clean up & \\
\hline & & [column, technique] & & \\
\hline $\begin{array}{l}\text { apple }^{\mathrm{a}} \\
{[5]}\end{array}$ & $\begin{array}{c}0.2 \\
\text { [ethyl acetate:hexane, 10] }\end{array}$ & $\begin{array}{c}10 \mathrm{~mL} \text { of ethyl acetate:hexane }(1: 1) \\
\text { shake for } 20 \text { min } 2 \mathrm{~g} \text { of } \mathrm{Na}_{2} \mathrm{SO}_{4} \\
{\left[\text { Nucleosil } \mathrm{NH}_{2}, \text { LC-UV] }\right.}\end{array}$ & No clean up & $\begin{array}{l}94 \\
(9)\end{array}$ \\
\hline $\begin{array}{l}\text { apple }^{b} \\
{[50]}\end{array}$ & $\begin{array}{c}0.2 \\
\text { [ethyl acetate, 100] }\end{array}$ & $\begin{array}{c}100 \mathrm{~mL} \text { of ethyl acetate } \\
30 \mathrm{~g}^{\text {of } \mathrm{Na}_{2} \mathrm{SO}_{4}} \\
\left.\text { [Lichrospher } 100 \mathrm{RP}_{18} \mathrm{LC}-\mathrm{UV}\right]\end{array}$ & GPC & $\begin{array}{l}89 \\
(11)\end{array}$ \\
\hline melon $^{\mathrm{c}}$ & 0.06 & $\begin{array}{l}200 \mathrm{~mL} \text { of acetone partition } \\
\text { with } 200 \mathrm{~mL} \text { of dichloromethane }\end{array}$ & GPC & $\begin{array}{l}88 \\
(8)\end{array}$ \\
\hline [100] & [acetone, 400] & $\begin{array}{c}\mathrm{Na}_{2} \mathrm{SO}_{4} \\
{[\mathrm{SPB}-608, \mathrm{GC}-\mathrm{ECD}]}\end{array}$ & & \\
\hline
\end{tabular}

GPC: gel permeation chromatography; a: present method $(n=4)$; b: ref. $4(n=5)$; c: ref. $6(n=3)$.

\section{CONCLUSIONS}

A simple, inexpensive and efficient liquid chromatographic method for determining clofentezine residues in apple, mango, orange and papaya was described. The method yields recoveries that ranged between $81-96 \%$. No clean up was necessary. Ethyl acetate as solvent extraction showed high effectiveness for clofentezine. However, more interfering peaks were observed in the chromatograms. The LOQ achieved by the method was in agreement with MRL values, making the method suitable for routine analysis.

\section{ACKNOWLEDGEMENTS}

S. Navickiene (Proc. n 98/15891-6) thanks FAPESP (Fundação de Amparo à Pesquisa do Estado de São Paulo) for fellowship.

\section{REFERENCES}

1. Tomlin, C.; The Pesticide Manual, Cambridge: BCPC, Crop Protection Publications, 1995, p. 219.
2. Roberts, T. R.; Hudson, D. H.; Metabolic Pathways of Agrochemicals, Cambridge: The Royal Society of Chemistry, 1999.

3. http://www.anvisa.gov.br/toxicologia/monografias, acessada em Setembro 2003.

4. Balinova, A.; J. Chromatogr. 1998, 823, 11.

5. Barnes, K. A.; Fussell, J.; Startin, J. R.; Thorpe, S. A.; Reynolds, S. I.; Rapid Commun. Mass Spectrom. 1995, 9, 1441.

6. Gelsomino, A.; Petrovicova, B.; Tiburtini, S.; Magnani, E.; Felici, M.; J. Chromatogr. 1997, 782, 105.

7. Scibaldi, E.; Sarra, A.; Mutti, D.; Bo, P. E.; J. Chromatogr. 1997, 765, 13.

8. Kaihara, A.; Yoshii, K.; Tsumura, Y.; Nakamura, Y.; Ishimitsu, S.; Tonogai, Y.; J. Health Sci. 2000, 46, 336.

9. Lasserre, Y.; Les Résidus de Pesticides dans les Fruits et Légumes et les Pommes de Terre dans les Pays dEurope Occidentale (EU, Suisse, Norvège), France: Centre Français du Commerce Exterieur, 1999.

10. Codex Alimentarius-Pesticide Residues in Food, Rome: Joint FAO/WHO Food Standards Programme, 1998.

11. Roteiro de Validação de Metodologia Analítica visando a Determinação de Resíduos de Pesticidas, Brasil: Laboratório Vegetal do Ministério da Agricultura, GARP, ANDEF, 1997.

12. Thier, H. P.; Zeumer, H.; Manual of Pesticide Residue Analysis, Verlag Chemie: New York, 1987, p. 37. 